\title{
PRICING ECONOMIC VALUE OF ORGANIC RICE UNDER DICHOTOMOUS CHOICE FRAMEWORK: AN ENVIRONMENTAL PERSPECTIVE
}

\author{
WANNINAYAKE W.M.C B. ${ }^{1+}$ AND A. ARUNA SHANTHA ${ }^{2}$ \\ Senior Lecturer $(\mathrm{PhD})^{1}$
}

Department of Marketing Management, University of Kelaniya, Sri Lanka

bwanninayake@gmail.com

PhD Candidate ${ }^{2}$

School of Economics, Collage of Business, Northern University of Malaysia, Malaysia

aru@sab.ac.lk

\begin{abstract}
In Sri Lanka, rice accounts for 25 percent of total cultivable land, and more than two million families are engaged in farming as their main occupation. Intensive paddy farming in Sri Lanka has destructive effects on land, water, animals and human. Growing organic rice rather than commercially produced rice is the environmentally healthy choice and it is a fast growing agricultural segment in Sri Lanka during recent decades. However, organic farming faces challenges such as higher management cost; the risks of learning new farming methods, a fragmented industry that is still young; higher cost of marketing the value of organic rice; and the higher cost of consumer engagement. Further, willingness to pay extra for organic products was less than anticipated. This study attempts to determine the economic value of organic rice by eliciting customers' willingness to pay (WTP) using contingent valuation method followed by single bounded dichotomous choices. Ecoliteracy, perceived importance and demographic variables were employed as independent variables for the study. A stepwise backward binary multivariate logistic regression model was used to measure WTP and to determine the factors that influence the variation in WTP. Primary data were obtained from 1,158 local customers from 36 supermarkets in Colombo districts. The study found that majority of local sampled customers (57.5\%) refused to pay any additional payment for organic rice even though it was environmentally friendly product. However, $42.5 \%$ sampled customers agreed to pay an additional payment for organic rice. As estimated parametric logistic model the mean value of WTP for green rice at higher bidding level is Rs. $126.71 / \mathrm{kg}$.
\end{abstract}


However, that value at medium bidding level was Rs. 98.61/kg and at low bedding level it was Rs. 81.78/kg. According to the empirical results $\mathrm{H} 1$ and $\mathrm{H} 2$ were fully supported and $\mathrm{H} 3$ were partially supported. In conclusion, policy makers can identify the range of price increase of such organic rice without damaging the existing demand for organic rice and it is a timely need to introduce new marketing strategies to expand the market segment in organic rice in Sri Lanka.

Keywords: Dichotomous choice framework, Willingness to pay, Organic rice, Logistic regression model, Green marketing

\section{Background}

The growing social and regulatory concerns towards the environment lead an increasing number of companies to consider green issues as a major source of strategic change (Wanninayake and Randiwela, 2008). Further growing customers concern and feeling of responsibility for society in global context make remarkable market growth for ecofriendly products (Hunt \& Dorfman, 2009). It is known as ethical consumerism or green consumption (Anderson \& Cunningham, 1972). In particular, this trend has major and complex implications on the overall strategic direction of the companies. As increasing eco-awareness of customers is a new trend in the world, ecologically oriented consumption becomes a crucial concept in consumer behavior. This condition demand for introducing environment friendly approach to the businesses and encourage stakeholders to pressure management of the companies to be green marketing oriented.

According to the general meaning given in the literature, green products are environmental friendly products. However, the past studies did not yet offer an objective definition of what makes a product "environmentally friendly" (Hartmann and Vanessa, 2006). According to previous authors, green product has environmentally sound production processes, responsible product uses, or product elimination, which consumers compare with those possessed by competing conventional products (Peattie, 1995). Therefore the green products are more expensive than the non-green products. Even though the market for green products is generally considered to be both established and expanding, marketers should overcome certain inherent negative characteristics of green products (Rex and Baumann, 2007). Those negative characteristics are considered as major challenges for eco marketing practitioners.

The main challenge of green products is that how to demonstrate or communicate the environmental friendliness of the products to target customers. In certain cases, governmental 
and non-governmental organizations facilitate to green marketing companies by introducing and maintaining trustworthy environmental labeling schemes (Rex and Baumann, 2007). The rationale behind those schemes is to facilitate consumers to recognize environmentally sound products. However most of past researchers argue that the customers may not ready to pay additional cost associated with green products. For instance some researchers noted that there is a "green backlash" (E.g. Rex and Baumann, 2007). However negative publicity about eroded green premium was influenced for reducing enthusiasm to buy the green and organic products (Mendleson, and Polonsky, 1995). Further willingness to pay extra for organic products was less than anticipated (Wasik, 1996). Moreover, Rex and Baumann (2007) explore that market share for green products have not changed significantly over the past few decades. According to de Boer (2003), environment claims of advertising of organic products may be subjected to criticism of consumer organizations and other pressure groups and sometimes face legal issues as well (Scammon and Mayer, 1995). Aforesaid literature has been remained valuable argument for current study as whether customers are willing to pay more on green or organic products and if they are willing to pay extra, how much is it. Further previous literature regarding this issue cannot be generalized to different context and different cultures. Therefore the present study focuses on this argument with special reference to the organic rice market in Sri Lanka.

\section{Objectives and Scope of the Study}

The main purpose of this research paper is to identify the market potentials and measure the customer's willingness to pay for organic rice in Sri Lanka. Further the study measures the impact of demographics variables, ecoliteracy and perceived importance on willingness to pay decisions on those products as well. For this purpose organic rice were chosen due to the emerging trend among consumers in most of the countries to use organic products over the carbonic products. Especially in Sri Lankan context, some scientists argue that agricultural products are contained very harmful chemicals like arsenic and those are directly related with serious diseases like kidney issues of the people in respective areas. Therefore demand for organic agricultural products is continuously increasing in the country. Further organic rice marketers in most of the countries adapted to the eco labeling as strategy to differentiate their brands from other counterparts and communicate environment values through their promotional campaigns.

In Sri Lanka, rice account for 25 percent of total cultivable land, and more than two million families are engaged in farming as their main occupation. Highly water-intensive rice 
cultivation consumes more than 70 percent of the total water allocated for food production in the country (Shantha, 2012). The principle irrigated crop, paddy is grown on nearly 730, 000 ha of land. The output of rice has witnessed a significant increase during the past three decades and this increase can be traced primarily to the expansion of cultivated area as well as to increased productivity. The latter is an outcome of the application of newer research findings on a variety of aspects such as improvement in genetic constitution of the crop, introduction of superior quality fertilizer, newer methods of plant establishment, and better methods of weed and pest control (Abeysekera, 1996).

Environmental health is damaged by intensive paddy farming and the benefit of organic paddy farming is significant and over time can repair the damage done. Intensive paddy farming in Sri Lanka has destructive effects on land, water, animals and human. Growing organic rice rather than commercially produced rice is the environmentally healthy choice. Organic rice farming is a fast growing agricultural segment in Sri Lanka during recent decades. However, organic farming faces challenges such as higher management cost; the risks of learning new farming methods, a fragmented industry that is still young; higher cost of marketing the value of organic rice; and the higher cost of consumer engagement. Therefore it is worth to investigate consumers' perception towards organic rice and their willingness to pay for it.

\section{Literature Review}

Generally green marketing can be defined as marketing of products or services by promoting environmental core values associated with the company products or brands (Rex and Baumann, 2007). Even though green marketing has become a very popular research area in 1980s and early 1990s, initially academics and researchers paid attention on this new marketing phenomena in 1970s (Straughan and Robert, 1999).

According to Polonsky (1994) green marketing incorporates a broad range of activities, including product modification, changes to the production process, packaging changes, as well as modifying advertising. However Rex and Baumann (2007) argue that there are two contrasting perspectives on green marketing. One is informing customers' environmental values through eco labeling and other perspective is developing supply and demand for the green products. Most of green marketing companies are mainly using the eco labeling as a dominant means of market communication for green credentials of products. However a sustainable production and consumption system is still far away. Due to the prevailing situation a majority of customers believe that green marketing refers solely to the promotion 
or advertising of products with environmental characteristics (Polonsky 1994) and terms like phosphate free, recyclable, refillable, ozone friendly, and environmentally friendly are some of the factors consumers most often associate with green marketing campaigns. However in general, green marketing is a much broader concept, one that can be applied to consumer goods, industrial goods and even services (Straughan and Roberts, 1999). Some researchers argue that value generated by green products with the environment friendliness is lower than cost incurred with them. Therefore green marketers must balance prices for green products with consumers' sensitivity to cost and their willingness-to-pay more for environmental safety (Jay, 1990). Further willingness to pay of customers can vary according to profile of those customers.

As per the previous literature, there are several factors which may influence on willingness to pay more for the green products. According to Laroche et. al. (2001), those factors were divided into five categories such as demographic, knowledge, values, attitudes and behavior. Further Diamantopoulos et.al. (2003) noted that the profile of green consumers can be identified based on several variables introduced by past researchers. Those are geographic measures (e.g. Pickett et. al., 1993), cultural measures (e.g., Anderson et. al.1974), personality measures (e.g., Crosby et. al., 1981), and, socio-demographic characteristics. However, most studies explored that value of socio-demographic characteristics for segmenting and targeting environmentally conscious consumers is little bit ambiguous (Stern et al., 1995). According to Straughan and Robert, (1999), most of researchers made attempts to identify correlation between demographic variables and ecologically conscious attitudes and/or consumption. The demographic characteristics of environment friendly customers were investigated by past researchers since 1970s. For instance Anderson and Cunningham (1972) investigated the profile of socially responsible customers. Most of the past studies have focused on age, gender, marital status, income, and education level of customers as main demographic variables.

Straughan and Robert, (1999) further noted that psychographic characteristics may correlate with the consumers' green attitudes and behaviors. They emphasized that political orientation, altruism, perceived consumer effectiveness, and environmental concern of customers etc. are the main psychological determinants of green consumer behavior. However the association of environmental consciousness is an important matter to be investigated. Environmental consciousness has been analyzed by previous researchers in wide range of social science disciplines, such as psychology and sociology (Macnaghten and 
Urry, 1995), political science (McCormick, 1995), environmental studies (Widegren, 1998), business research (Minton and Rose, 1997) and marketing (Ling-yee, 1997). Even though most of measurement have been used to operationalized the environmental consciousness of customers, most of the researchers had noted that it consists of knowledge about green issues, attitudes towards environmental quality, and levels of environmentally sensitive behavior (e.g. Balderjahn, 1998). According to Rao and Bergen, (1992) willingness to pay of customers for any product is determined by its intrinsic and extrinsic features. Accordingly in the case of green products, the price premium should be fair to the additional value delivered by the products. Further Irland, (1993) noted that customers may not always make their buying decisions based on the environmental attitudes; however it is becoming an extremely important factor in buying decisions. In this context, the present study is aimed at exploring the impact of ecoliteracy, perceived importance and demographic factors on consumer wiliness to pay on green products such as organic rice in Sri Lanka.

\section{Conceptual Framework and Hypotheses}

The main argument of the study is that whether consumers willing to pay additional premium on organic rice and how far ecoliteracy, perceived importance and demographic variables influence on this condition. According to the previous literature, environmental consciousness has direct influence on consumer willingness to pay additional premium for protecting environment. Further Laroche et. al. (2001) noted that environment consciousness of customers mainly determined by ecoliteracy, values, behavior of purchasing green products and customer attitudes towards environment friendly products. Further those authors argued that attitude of customers towards green products directly associated with perceived importance of buying ecofriendly products as well. Based on the previous literature, present researchers have selected ecoliteracy, perceived importance and demographic variables as independent variables and consumer willingness to pay on organic rice as dependent variable for this study. Accordingly figure 01 shows the path model for demonstrating the hypothesized relationships among these variables in this study.

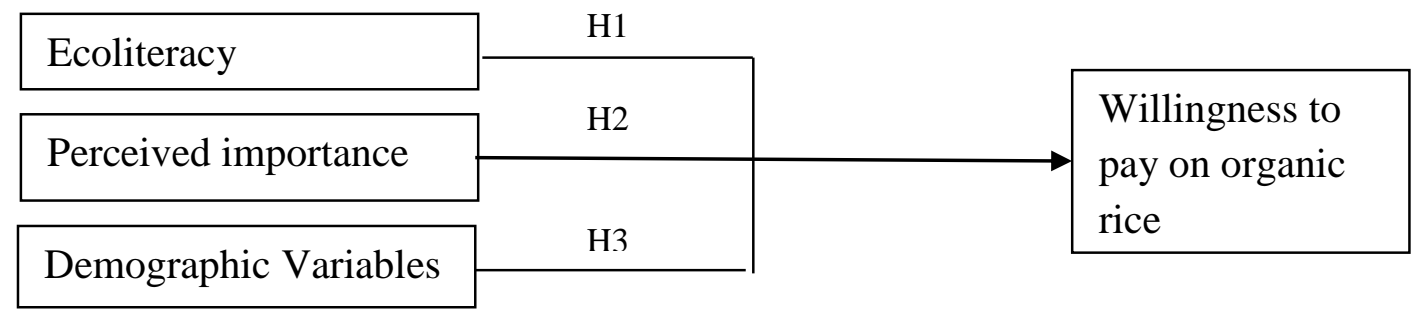

\section{Fig 01: Conceptual Framework}


Customer knowledge about the environment is known as ecoliteracy and it may directly influence on the green consumer behavior since it provides factual information to customers about the environment (Diamantopoulos et. al. 2003). According to Laroche et. al. (2001) consumer knowledge towards environment may determine the ability of customers to identify or define a number of ecologically- related symbols, concepts and behaviors. However there is no common agreement among previous researchers about consumers' environment knowledge and ecologically compatible behavior (Laroche et. al., 2001). For instance, Chan (2001) noted that ecoliteracy is a significant predictor of environment friendly behavior. On the other hand Moloney and Ward (1973) explored that there is no significant relationship between environment knowledge and ecologically compatible behavior. They further argued that there is no compulsory requirement to have sound knowledge about environment to hold positive attitude towards green products. Based on the aforesaid arguments, researchers developed the first hypothesis to empirically test the argument in the present research context.

H1: Customers are willing to pay higher price for organic rice, when they have sound knowledge about the environment (high ecoliteracy).

Environmental attitudes of customers has direct impact on purchasing decision (Schwepker and Cornwell, 1991) and usage intentions (Alwitt and Berger, 1993) of customers. Further if customers are more involved with environment, they are more likely to buy green products (Schuhwerk and Lefkokk-Hagius, 1995). According to past researchers (e.g. Antonides and van Raaij, 1998), there is controversy between attitudes and actual behavior relationship. They argue that attitude alone may not accurately predict actual behavior. Lee and Green, (1991) noted that weak relationship between attitudes and behavior in the environmental and social marketing literature. Further in case of buying green products, customers may expect to understand results of their actual behavior (Bohlen et al., 1993). Environmentally sensitive behavior, directly influence on current past and future commitment of customers towards protect natural environment (Roozen and De Pelsmacker, 1998). As Laroche et. al. (2001) argues the perceived importance represents the attitudes of customers towards environment friendly products. Amyx et. al. (1994) defined perceived importance as "the degree to which one express concern about ecological issues". That means how consumers believe environmentally compatible behavior is important to them and to the society as whole. Most of the previous researchers (e.g. Banerjee and McKeage, 1994) argue that perceived importance of environment friendly behavior is strong motivation to pay high prices for 
ecofriendly products. Considering those arguments, the second hypothesis for this study has been formulated as follows:

$\mathrm{H} 2$ : Customers are willing to pay higher price for organic rice, when they are perceived high importance of environmentally compatible behavior.

As per the above discussion, Laroche et al. (2001) noted that the study of demographic profiles of environment friendly customers can be traced back to the late 1960s. However there is no common agreement among those researchers about the demographic factors of socially responsible customers. Anderson and Cunningham (1972) concluded that high socially conscious person is young educated female who represents above average socioeconomic status. Further Diamantopoulos et al., (2003) argue that educational level and social class are the main determinants of the environment consciousness of the customers. Even though early researchers identified that green consumers are younger than average, some recent studies (e.g. Robert, 1996) explored that green customers are older than average. Furthermore Robert (1996) noted that previous literature about green consumer behavior and their demographic characteristics are contradictory. However most of previous authors believe that demographic factors exert a significant influence on environment friendliness of people. On the other hand some researchers noted that demographic factors are less important than ecoliteracy and human values in the case of green consumer behavior. Therefore, the researchers have developed $\mathrm{H} 3$ to determine the relationship between demographic factors and green consumer behaviour.

H3: Demographic variables have a significant influence on the willingness to pay higher price for organic rice. Specifically, (a) Age, (b) Gender, (C) Income, (d) Education, and (e) marital status will have a significant influence on the willingness to pay price premium for organic rice.

\section{Materials and Methods}

The theoretical model of the study is based on standard microeconomics principles and empirical work cited in the literature review section. Contingent Valuation Survey (CVS) stimulates to identify the market for a non-market good and obtains a value for those products (Wedgwood \& Sansom, 2003). Therefore CVS is a unique method that can estimate the value of non-market goods as well (Samdin, 2008). Contingent valuation elicitation questions may be open-ended or closed-ended. In an open-ended question the respondent is asked to state the maximum amount that he or she is willing to pay for the good or service that is being 
valued (Arrow, et.al 1993). Under closed-ended contingent valuation CV question or "dichotomous choice" approach the respondent is asked whether he or she is willing to pay a specific amount presented as the value of the improved service (Gunathilaka, et.al 2007). In this study researchers applied dichotomous choice approach and since dependent variables were collected binary data, logistic model was applied to estimate WTP. The study applied dichotomous choice framework with logistic model for measuring economic value for organic rice which are staple food crops in Sri Lanka. The reduced form of a typical logistic probability model for willing to pay on proposed price for organic rice and factors effecting for their decision can be written in the following form:

$\operatorname{Pr}\left[\mathrm{Y}_{\mathrm{t}=1}\right]=\frac{e^{\beta x}}{1+e^{\beta x}} \quad \operatorname{Pr}\left[\mathrm{Y}_{\mathrm{t}=1}\right]=\frac{e^{\beta 0+\beta 1 B I D+\sum_{i=1}^{n} \gamma i S i+\sum_{j=1}^{m} \propto j F j}}{1+e^{\beta 0+\beta 1 B I D+\sum_{i=1}^{n} \gamma i S i+\sum_{j=1}^{m} \propto j F j}}$

Where,

$Y=$ Agreed or not for proposed specific amount for organic-rice (Proposed bid levels were $10 \%$ greater than the current carbonic rice)

$1=$ willing to-pay, $0=$ not willing-to-pay

$B I D(X 1)=$ Visitors Bid level for organic rice $($ Rs. per $K g)$

$S=$ Visitors Demographics characteristics

INC (X2) = Monthly Income of visitor (Sri Lankan Rupees)

NIS $(X 3)=$ No of income sources

MS (X4) = Marital States; (1) Married, (0) Otherwise

Age $(X 5)=$ Years

SEX $(X 6)=(1)$ Male $;(0)$ female

$T E(X 7)=$ Type of Employment $(1)=$ White color job $(0)=$ Otherwise

EDC $(X 8)=$ Education: Respondents education level (lastly reached grade)

$F=$ Ecoliteracy and Perceived Importance

ECO $(X 9)=$ Ecoliteracy 
07 items five point likert's scale adopted by Laroche et al. (2001) for measuring consumer knowledge about the environment

$P I(X 10)=$ Perceived Importance

Selected 06 items from the 17 statements (five point likert's scale) adopted by Robert (1996) to measure customer attitudes towards environment.

\section{Sampling Framework and Data Gathering Tools}

This study undertakes two phases, firstly a preliminary meeting and discussion with the relevant producers on existing pricing policies on non-organic rice and propose new bidding strategies for organic rice. The additional cost of organic rice was measured with the information given by existing organic rice producers. The bidding levels of selected green products were determined based on additional cost incurred for organic rice at production and marketing stages. The questionnaire was sensibly developed following seven pillars of CV survey which was introduced by NOAA panel (Arrow at el, 1993). The survey questionnaire was chosen because it encouraged high response rate and was suitable for complex questions. The questionnaire was divided into two sections. The first section covered the socioeconomic characteristics of visitors and paying capabilities for organic rice. Ecoliteracy and perceived importance of customers were covered in second section of the questionnaire. To discover the willingness to pay for organic rice from selected customers, study applied the bidding game approach which involved three different prices (low, medium and high) for selected green products. First, higher price was proposed and responses were checked. If they refused at the first bidding level, second one or third one was proposed. Three bidding levels were proposed to the customer until he or she agreed with the most suitable one. Systematic sampling procedure was used at personal interviews. Every fourth visitor who exits from the selected supermarkets in Colombo districts was chosen as a sample since such supermarkets usually serve to both high income and medium classes. The survey was conducted covering 1,158 local customers from 36 supermarkets in Colombo districts during the period of April and May 2012.

\section{Results, Discussion and Conclusion}

\section{Visitors' Profiles}

The majority of customers were between 30-45 year of age (48\%) and 20-29 years of age (42\%) and insignificant percentage above 65 years old (2\%). Balance was below 20 years old 
(8\%). By gender, the majority of customers were (54.8\%) males and more than half were married (58.7\%). According to the survey, $72 \%$ of local customers' monthly income was more than SLR 25,000 and balance was below SLR 25,000. In terms of educational background $35 \%$ of visitors (out of total) had completed secondary education. Beside $29 \%$ and $18 \%$ visitors had reached basic degree and master qualification respectively. The customers' most popular type of transportation to supermarket was their own vehicles $(46.2 \%)$ and only (22.1\%) has reached to supermarket by their three wheelers. Another $21 \%$ of customers have been used public transport services to reach the supermarkets.

\section{Contingent Valuation of Organic Rice}

Under this section, respondents were asked two questions. First, respondents were asked whether they were willing to pay the additional payment for organic rice. Thus, first question was a dichotomous choice question or closed-ended question. If the answer was "Yes", the enumerators were moved to next part of the questionnaire. Where the answer was "No" such respondents were post to discover their opinion on 'disagreed to paying' additional payment on organic rice. If the answer was "Yes" such respondents were post to discover their opinions on the level of paying for organic rice. At the beginning, enumerators proposed medium level of fee to cover the additional cost occurred with organic rice and if they accepted suddenly, proposed higher bidding rate. Conversely, as they rejected medium bidding rates then post to lower one which is below the additional cost incurred with organic rice. This approach is called "Bidding Game" and used three bidding rates for three types of green products since the study covered a reasonable sample. Proposed prices were developed by reviewing existing pricing policies and recent literature on organic rice. Surprisingly, majority of local customers were disagreed with the proposed bidding rates for organic rice. Out of 1,158 customers only $16.7 \%$ were agreed to pay lower bidding level and $14 \%$ customers agreed to medium bidding level for organic rice. Only $11.8 \%$ have agreed with higher bidding levels. However, majority of customers (57.5\%) have refused to pay any additional payment for organic rice.

The majority of the visitors who disagreed to pay extra premium, stressed that the existing income level did not support to paying any additional payment for organic rice. More specially, existing cost of living conditions and insufficient sources of income were highlighted as the main reasons for their disagreements for proposed bidding levels on organic rice. A parametric logistic probability model was employed to estimate central tendency measures of WTP for selected organic rice (Gunathilaka, et.al., 2007). To calculate 
the mean value of WTP for entrance permit, divide the coefficient on constant (i.e., 24.40) by the coefficient on BID (i.e., 0.246) and multiply by -1 (Hair et.al., 2010). The study gets a value of about Rs.99.21, which is the mean WTP for the total agreed sample for organic rice. Similar procedure was applied for measuring WTP at different bidding levels as depicted in table no 01.

Table 01: Mean value of WTP for organic rice under different bidding levels

Statistics
WTP for Entrance Permit

$(\mathrm{Rs} / \mathrm{kg})$
Mean WTP ${ }^{\mathrm{a}}$ (Agreed to higher bidding level Customers)

Standard error

No of observations

Mean WTP ${ }^{\mathrm{a}}$ (Agreed to medium bidding level Customers)

Standard error

No of observations

Mean WTP ${ }^{\text {a }}$ (Agreed to low bidding level Customers)

Standard error

No of observations

Mean WTP ${ }^{\mathrm{a}}$ (Total agreed customers)

Standard error

No of observations

Mean WTP ${ }^{\text {a }}$ Total customers, Agreed + Disagreed)

Standard error

No of observations

Notes: ${ }^{a}$ Mean of WTP calculated based on estimated linear-logistic regression. It is E (WTP)

$=\left(\beta^{0} / \beta^{1}\right)^{*}-1$, Where $\beta^{0}$ is the estimated constant and $\beta^{1}$ is estimated coefficient of bid level.
98.61

33.98

162

81.78

28.78

139

99.21

45.98

66.78

58.43

1,158

Source: Logistic Regression Model. 
The results of WTP for entrance permit are presented in table 01. As estimated parametric logistic model the mean value of WTP for organic rice at higher bidding level is Rs. $126.71 / \mathrm{kg}$. However, that value at medium bidding level was Rs. 98.61/kg and at low bedding level it was Rs. $81.78 / \mathrm{kg}$. It is important to note that almost all the agreed customers average WTP price for green rice was Rs.99.21 per $\mathrm{kg}$ and it was $42 \%$ ahead the existing average non-organic rice price in Sri Lanka.

\section{Factors Explaining WTP for Organic Rice}

A stepwise backward binary multivariate logistic regression model was applied to determine the key factors associated with willing to pay decision of agreed 497 local customers to organic rice. Here, the socio-economic and demographic characteristics of visitors were considered. Initial model was run with 11 explanatory variables; however after the $7^{\text {th }}$ iteration model was selected, it was possible to determine ten key factors which mainly influenced respondent's decisions. Selected variables, their beta values and the level of significance of each estimated beta values are as follows:

Table 02: Important Indicators of the Estimated Logistic Model - Total Customers

\begin{tabular}{lccccc}
\hline Variables in the equation & B & Std.Error & Wald & Sig & $\operatorname{Exp}(\beta)$ \\
\hline BID(X1) & 0.246 & 0.157 & 16.781 & 0.001 & 1.279 \\
INC(X2) & 0.558 & 0.343 & 9.562 & 0.012 & 1.823 \\
NIS(X3) & 0.601 & 0.319 & 5.321 & 0.013 & 1.824 \\
EDU(X7) & 0.247 & 0.190 & 4.776 & 0.016 & 1.280 \\
TE(X8) & 0.211 & 0.002 & 6.582 & 0.012 & 1.235 \\
ECO(X9) & 0.458 & 0.259 & 11.234 & 0.002 & 1.580 \\
PIC(X10) & 0.389 & 0.283 & 6.287 & 0.011 & 1.475 \\
CONSTANT(X11) & -16.42 & 1.193 & 22.085 & 0.000 & 0.000 \\
\hline
\end{tabular}

Note: $\beta=$ Logistic coefficient, $\operatorname{Exp}(\beta)=$ exponentiated coefficient, $\mathrm{N}=1,158$.

Source: Logistic Regression Model

The summary statistics of the goodness of fit and estimated coefficients are presented in table no 02. The socio-economic impacts on WTP were discussed based on total customer's model as depicted in table 02. In this final model almost all the variables except constant have 
positive signs, indicating the positive relationship between dependent variables and predicted probability. Among selected explanatory variables under final model, visitor's income was the most influential variable for willingness to pay decision. As visitors income increased, they have shown higher bidding level for organic rice. Secondly, those who have more than single income sources they have reflected higher obligation for WTP than others. Thirdly, customers, who have had white color jobs, have shown higher commitment on willing to pay for organic rice than other employments. Further, customers' educational level, ecoliteracy, and perceived importance have recorded positive impact on WTP for organic rice. This result indicates the universal fact that the knowledge enhances the awareness in value of natural environment. However, age, sex and marital status were rejected from the final model, since those variables did not reflect significant impact on WTP decision for organic rice. All those results were consistent with theoretical expectation and empirical findings.

\section{Magnitude of the Relationships}

The degree of probability change in a given one-unit can be estimated based on change in the independent variable or change in WTP. In this study there were two types of independent variables: metric and non-metric variables (Dummy). Thus, magnitude of the relation was described under two sections.

\section{Metric Independent Variable}

The most direct method of assessing the magnitude of the change in probability due to each metric independent variable is to examine the exponentiated coefficient (Hair et.al, 2010). The exponentiated coefficient minus one into 100 equals the percentage changes in odds due to one unit change in independent variable.

According to table no 03, all estimated exponentiated coefficients are greater than one except intercept and it denotes positive relationship with dependent variable as concluded previously. According to the value of percentage change in odds, a one unit change in visitor's income will increase the odds by $82.3 \%$. It was evident that higher income holders were extremely committed to paying higher price for organic rice than low income holders. 
Table 03: Percentage Change in Odds in Metric Variables (Total Customers)

\begin{tabular}{lccc}
\hline \multicolumn{1}{c}{ Variables } & $\begin{array}{c}\text { Percentage change in } \\
\text { Odds }^{\mathrm{a}}\end{array}$ & $\operatorname{Exp}(\beta)$ & Significance \\
\hline $\mathrm{BID}(\mathrm{X} 1)$ & 27.9 & 1.279 & 0.001 \\
$\mathrm{INC}(\mathrm{X} 2)$ & 82.3 & 1.823 & 0.012 \\
$\mathrm{NIS}(\mathrm{X} 3)$ & 82.4 & 1.824 & 0.013 \\
$\mathrm{EDU}(\mathrm{X} 7)$ & 28.0 & 1.280 & 0.013 \\
$\mathrm{ECO}(\mathrm{X} 9)$ & 58.0 & 1.580 & 0.002 \\
$\mathrm{PIC}(\mathrm{X} 10)$ & 47.5 & 1.475 & 0.017 \\
\hline
\end{tabular}

Note ${ }^{\mathrm{a}}=\mathrm{e}^{\mathrm{b}}{ }_{\mathrm{i}-1} 1^{*} 100$, Source: Logistic Regression Output

Source: Logistic Regression Model

As one unit change (increased) in customer's income sources leads to increase the odds by $82.3 \%$, customer's number of income sources was also more effective factor behind demand. Further, a one unit increased in customer's ecoliteracy, leads to increase the odds by $58 \%$. Finally, a one unit increased in perceived importance, WTP for organic rice will be increased by $47.5 \%$.

\section{Nonmetric Independent Variables - Total Customers}

The exponentiated coefficients are the best means of interpreting the impact of the dummy variable but are interpreted differently from the metric variable (Hair et.al, 2010). Exponentiated coefficient represents the percentage of the odds ratio of customers who agreed to pay the proposed price package for organic rice compared to disagreed customers. The reason is 1 stated for agreed customers and 0 stated disagreed customers in the model. Thus, summarized nonmetric coefficients are given in table 04 .

Table 04: Magnitudes of nonmetric variables (Total Visitors)

\begin{tabular}{ccc}
\hline Variable & $\operatorname{Exp}(\beta)$ & Significance \\
TE $(\mathrm{X} 8)$ & 1.235 & 0.012 \\
\hline
\end{tabular}

Source: Logistic Regression Output 
Among exponentiated coefficients, types of employment have been associated with the willingness to pay decision. Types of employment' coefficient is 1.235 means that, white color workers have 23.5 percent higher odds than blue color workers $(1.235-1=0.235)$. Simply, white color job workers were 23.5 percent higher enthusiastic for paying proposed biding prices for organic rice than other jobs categories.

\section{Assessing Overall Model Fit}

The first statistical measure is the chi-square test for the change in the -2LL value from the base model. In this exercise the -2LL value has reduced from the based model value of 361.098 to 103.21 , a decrease of 257.888 as shown in table 05 . This increase in model fit was statistically significant at 0.000 levels. However the -2LL value has reduced from prior model by 6.357 . This increase in model fit was significant at the 0.808 level.

Table 05: Overall Model Fit

\begin{tabular}{lll}
\hline Change in -2LL (-2 Log Likelihood) & Change & Significance \\
\hline From Base Model & 257.888 & 0.000 \\
From Prior Step & 6.357 & 0.808 \\
\hline
\end{tabular}

Source: logistic Regression Output

Note: Initial -2 Log Likelihood is 361.098 and with final step it is 103.21

\section{Hosmer and Lemeshow Test}

Hosmer and Lemeshow test also measure the overall fit of the model. This test measures the correspondence of the actual and predicted values of the dependent variable. The better model fit is indicated by a smaller difference in the observed and predicted classification. In this case significance level has reduced to 0.802 as shown in table 06 . A non-significant value indicating that the model fit is acceptable while it does not remain a significant difference between actual and expected values.

Table 06: Hosmer Lemeshow Test

\begin{tabular}{ccc}
\hline Step & Chi-Square & Significance \\
\hline 1 & 3.127 & 0.912 \\
2 & 2.211 & 0.965 \\
3 & 3.587 & 0.802 \\
\hline
\end{tabular}

Source: logistic Regression Output 


\section{Pseudo $R^{2}$ Measures}

There are three $\mathrm{R}^{2}$ measures in logistic regression model as in table 07 . All those indicators measure based on the reduction in the $-2 \mathrm{LL}$ value. In combination, all these three measures the variation of odds due to selected explanatory variables and it represent overall model fit. In this case Pseudo $\mathrm{R}^{2}$ is 0.741 indicating that the logistic regression model accounts for at least $74 \%$ variation of dependent variable. The hit ratio is $82.3 \%$ n indicates that the regression model predictive capacity is more than $89 \%$. (89.3\% of analysis sample correctly classified).

Table 07: Measures of Pseudo $\mathbf{R}^{2}$

\begin{tabular}{|l|c|}
\hline Measures of $\mathbf{R}^{\mathbf{2}}$ & Value \\
\hline Cox and Snell R & \\
Nagelkerke R & 0.556 \\
Pseudo R & 0.831 \\
Hit Ratio $^{* *}$ & 0.741 \\
\hline
\end{tabular}

Source: Logistic regression Output

Note: ** Percentage correctly classified.

\section{Conclusions and Policy Implications}

Dichotomous choice framework is a unique method that can be applied to measure the economic value of non-market goods including natural resources (Easter, et.al 1997). The study found that majority of local sampled customers $(57.5 \%)$ refused to pay any additional payment for organic rice even though it was an environmentally friendly product. However, $42.5 \%$ sampled customers agreed to pay an additional payment on organic rice. As estimated parametric logistic model the mean value of WTP for green rice at higher bidding level is Rs. $126.71 / \mathrm{kg}$. However, that value at medium bidding level was Rs. 98.61/kg and at low bedding level it was Rs. $81.78 / \mathrm{kg}$. It is important to note that almost all the agreed customers average WTP price for green rice was Rs.99.21 per kg and it was 42\% ahead the existing average non-organic rice price in Sri Lanka. Among selected explanatory variables under final model, visitor's income was the most influential variable for willingness to pay decision on organic rice. As visitors income increased, they have shown higher bidding level for organic rice. Secondly, those who have more than single income sources they have reflected 
higher obligation for WTP for organic rice than others. Thirdly, customers, who have had white color jobs, have shown higher commitment on willingness to pay for organic rice than other employments. Further, as customers' educational level, ecoliteracy, and perceived importance have recorded positive and significant impact on WTP for organic rice. However, age, sex and marital status were rejected from the final model, since those variables did not reflect significant impact on WTP decision for organic rice. According to the empirical results discussed in above section, $\mathrm{H} 1$ and $\mathrm{H} 2$ were fully supported and $\mathrm{H} 3$ was partially supported. Therefore all those results were consistent with theoretical expectation and empirical findings.

The optimum pricing strategy should be a combination of information gathered from agreed and disagreed customers on WTP for green products in Sri Lanka. Since, both agreed and disagreed customers willing to pay price for organic rice was just Rs.66.78 or 11.3 percent greater than the normal average rice price and it was insufficient to recover the additional cost of organic rice production. Thus, the study concluded that on average the organic rice production process is not economically viable production practice still in Sri Lanka. However, $42.5 \%$ sampled customers were agreed to pay 65 percent higher price for organic rice than normal rice. It means, the customers under middle and high income categories were willing to pay an additional payment on green rice and that payment is sufficient to cover additional cost on organic rice. Thus, policy makers can impose price discrimination strategy between different income categories and local organic rice producers could be encouraged for further production. In conclusion, the outcome of this study can be used as a tool for revising the existing pricing policies on organic rice in Sri Lanka. Further; policy makers can identify the range of price increase of such organic rice without damaging the existing demand for organic rice and it is a timely need to introduce new marketing strategies to expand the market segments in organic rice in Sri Lanka. Specially marketers should recognize most attractive segments for the organic rice and encourage the demand by enhancing importance of protecting natural environment.

\section{References}

Alwitt, L. F., \& Berger, I. E. (1993). Understanding the link between environmental attitudes and consumer product usage: Measuring the moderating role of attitude strength. Advances in Consumer Research, 20,189-194. 
Amyx, D.A., DeJong, P.F., Lin, Chakraborty, G. \& Wiener, J.L. (1994). Influencers of purchase intentions for ecologically safe products: an exploratory study. Proceedings of AMA Winter Educators' Conference (pp. 341-347). Chicago, USA: American Marketing Association,.

Anderson T.W, Henion KE \& Cox E.P (1974). Socially vs. ecologically concerned consumers. Proceedings of AMA Combined Conference (304-311). Chicago, IL: American Marketing Association.

Anderson, T. Jr \& Cunningham, W.H. (1972). The socially conscious consumer. Journal of Marketing, 36(7), 23 - 31.

Antonides G. \& van Raaij F.W. (1998). Consumer behaviour: a European perspective. Baffins Lane: Wiley.

Arrow, K., Solow, R., Portney, P., E.E, L., Radner, R., \& Schuman, H. (1993). Report of the NOAA panel Contingent Valuation. 58(10), 4601-4614.

Balderjahn I (1998). Personality variables and environmental attitudes as predictors of ecologically responsible consumption patterns. Journal Business Research 17(1), 51-56.

Banerjee, B. \& McKeage, K. (1994). How green is my value: exploring the relationship between environmentalism and materialism. Advances in Consumer Research, 21,147-52.

Bohlen G.M., Schlegelmilch B.B. \& Diamantopoulos A. (1993). Measuring ecological concern: a multi-construct perspective. Journal of Marketing Management 10(4), 415- 430.

Chan \& Ricky Y.K. (2001). Determinants of Chinese Consumers' Green Purchase Behavior. Psychology \& Marketing, 18 (4), 389-402.

Crosby L.A., Gill J.D. \& Taylor J.R. (1981). Consumer/voter behavior in the passage of the Michigan container law. Journal of Marketing, 45, 19-32.

De Boer, I., (2003). Environmental impact assessment of conventional and organic milk production. Livestock Production Science, 80, 69-77.

Diamantopoulos, A., Schlegelmilch, B.B., Sincovics, R. R., \& Bohlen, G. M. (2003). Can Socio-Demographics Still Play a Role in Profiling Green Consumers? A Review of the Evidence and Empirical Investigation. Journal of Business Research, 56, 465-480. 
Gunathilaka, H., Chen, J., Pattanak, S., \& Chde, K. (2007). Good practices for Estimating Reliable williness-to-pay value in the water supply and sanitation sector. ERD technical notes series , No 23. Phillipines: Asian Development Bank, Economic and Research Department.

Hair Jr, J., William , C., Barry, J., \& Rolph, E. (2010). Multivariate Data Analysis (Seventh Edition). New Jersey: Pearson.

Hartmann, P \& Ibanez, V.A (2006). Green value added, Marketing Intelligence \& Planning, 24(7), 673-80.

Hunt, N., \& Dorfman, B. (2009). How green is my wallet? Organic food growth slows. Reuters. Retrieved May 20, 2013, from http://www.reuters.com

Irland, L.C. (1993). Wood producers face green marketing era: environmentally sound products. Wood Technology, 120, $34-41$.

Jay, L. (1990). Green about the tills: markets discover the eco-consumer. Management Review, 79, 24-29.

Laroche, M., Bergeron, J., \& Barbaro-Forleo, G. (2001). Targeting Consumers Who Are Willing to pay more for Environmentally-Friendly Products. Journal of Consumer Marketing, $18(6), 503-520$.

Lee C. \& Green R.T. (1991), Cross-cultural examination of the fishbein behavioral intentions model. Journal of International Business Studies 22(2), 289-305.

Ling-yee L. (1997). Effect of collectivist orientation and ecological attitude on actual environmental commitment: the moderating role of consumer demographics and product involvement. Journal of International Consumer Marketing 9(4), 31-53.

Macnaghten P. \& Urry J. (1995). Towards a sociology of nature. Sociology 29(2):203-20.

Maloney, M.P. \& Ward, M.P. (1973). Ecology: let's hear from the people: an objective scale for the measurement of ecological attitudes and knowledge. American Psychologist, 7, 583586.

McCormick J. Rio \& Beyond (1995). The global environmental movement. Chichester: Wiley.

Mendelson, N., \& Polonsky, M.J. (1995). Using strategic alliances to develop credible green marketing. Journal of Consumer Marketing, 12(2), 4-18. 
Minton A.P. \& Rose R.L (1997). The effects of environmental concern on environmentally friendly consumer behavior: an exploratory study. Journal of Business Research, 40(1), 37 48.

Peattie, K. (1995). Environmental Marketing Management, London: Pitman Publishing.

Pickett G.M, Kangun N. \& Grove S.J.(1993). Is there a general conserving consumer? A public policy concern. Journal of Public Policy Marketing, 12(2), 234- 243.

Polonsky, M.J. (1994). An Introduction to Green Marketing. Electronic Green Journal, 1(2), $1-10$.

Rao, R.A. \& Bergem, M.E., (1992), Price premium variations as a concequence of buyer's lack of information. Journal of consumer behavior, 19(3), 412-423.

Rex, E. \& Baumann, H. (2007), Beyond ecolabels: What green marketing can learn from conventional marketing. Journal of cleaner production, 15, 567-576.

Roberts J. A.(1996). Green consumers in the 1990s: profile and implications for advertising. Journal of Business Research, 36(3), 217-31.

Roozen I.T.M. \& DePelsmacker P. (1998). Attributes of environmentally friendly consumer behavior. Journal of International Consumer Marketing, 10(3), 21 -41.

Samdin, Z. (2008). Willingness to Pay in Taman Negara: A Contingent Valuation Method. International Journal of Economic and Management, 2(1), 81-94.

Scammon, D. L., \& Mayer, R. N. (1995). Agency review of environmental marketing claims: Case-by-case decomposition of the issues. Journal of Advertising, 24 (2), 33-43.

Schuhwerk, M.E. \& Lefkokk-Hagius, R. (1995). Green or non-green? Does this type appeal matter when advertising a green product? Journal of Advertising, 24, 45-55.

Schwepker, C.H. Jr \& Cornwell, T.B. (1991). An examination of ecologically concerned consumers and their intention to purchase ecologically-packaged products, Journal of Public Policy and Marketing, 10 (2), 77-101.

Stern P.C, Dietz T. \& Guagnano G.A.( 1995). The new ecological paradigm in socialpsychological context. Environment Behaviour, 27(6), 723- 43.

Straughan R. D. \& Roberts, J. A. (1999). Environmental segmentation alternatives: a look at green consumer behavior in the new millennium. Journal of Consumer Marketing, 16(6), 558 -575 . 
Wanninayake W.M.C.B, Randiwela. P (2008). Consumer attractiveness towards green products of FMCG sector: an empirical study, Proceedings of Oxford Economics and Business Conference, Oxford University, UK.

Wasik, J.F. (1996). Green marketing \& management. Oxford; Blackwell.

Wedgwood, A., \& Sansom, K. (2003). Willing-to-Pay Surveys: Streamlined Approach. Loughborough University. U.K: Water Engineering \& Development Centre.

Widegren O.(1998). The new environmental paradigm and personal norms. Environment Behaviour, 30(1), $75-100$. 